BioLink : Jurnal Biologi Lingkungan, Industri dan Kesehatan, Vol. 6 (1) Agustus (2019)

ISSN: 2356- 458X (print) ISSN: 2550-1305 (online)

DOI: 10.31289 /biolink.v6i1.2210

BioLink

Jurnal Biologi Lingkungan, Industri, Kesehatan

Available online http://ojs.uma.ac.id/index.php/biolink

\title{
UJI AKTIVITAS ANTIBAKTERI EKSTRAK DAUN SERAI WANGI (CYMBOPOGON NARDUS) TERHADAP BAKTERI PROPIONIBACTERIUM ACNES
}

\section{ANTIBACTERIAL ACTIVITY OF SERAI WANGI LEAF EXTRACT (CYMBOPOGON NARDUS) AGAINST PROPIONIBACTERIUM ACNES}

\author{
Brigad Mahardika Winato, Erfan Sanjaya, Lisdawaty Siregar, \\ Solinia Kifami Yohana Maria Vianne Fau, Maya Sari Mutia*
}

Program Studi Pendidikan Dokter, Fakultas Kedokteran, Universitas Prima Indonesia, Medan

Diterima : 29-01-19; Disetujui : 26-04-19: Diterbitkan : 12-08-19

*Corresponding author: E-mail: *mayasarimutia@ymail.com

\begin{abstract}
Abstrak
Jerawat adalah penyakit pada kulit yang sering terjadi pada saat usia remaja hingga saat usia dewasa. Jerawat ditandai dengan munculnya beberapa tanda yaitu komedo, pustul, papul, kista dan nodus pada daerah leher, wajah, lengan atas, punggung dan dada. Jerawat juga merupakan penyakit kulit yang menyerang lebih dari 85\% kalangan usia remaja di seluruh dunia. Meskipun tidak mengancam jiwa, jerawat dapat mempengaruhi kualitas hidup seseorang dengan memberikan efek psikologis yang buruk bagi penderita berupa cara seseorang menilai, menanggapi dan memandang kondisi dan situasi dirinya. Tujuan penelitian ini adalah mengetahui daya hambat ekstrak daun serai wangi (Cymbopogon nardus) terhadap pertumbuhan bakteri Propionibacterium acnes. Penelitian dilakukan dengan metode eksperimental dengan desain postest hanya kontrol desain grup yang dilakukan di Lab Mikrobiologi Fakultas Kedokteran Universitas Prima Indonesia dan Lab Farmasi dan Toksikologi Fakultas Farmasi Universitas Sumatera Utara. Hasil penelitian menunjukan bahwa ekstrak daun serai wangi memiliki daya hambat terhadap pertumbuhan bakteri Propionibacterium acnes dengan berbagai konsentrasi yaitu 20, 40, 60, 80 dan 100\%. Semakin tinggi konsentrasi ekstrak daun serai wangi maka daya hambatnya semakin baik.
\end{abstract}

Kata Kunci: Ekstrak daun serai wangi, Jerawat, Propionibacterium acnes

\section{Abstract}

Acne is a disease of the skin that often occurs during adolescence until adulthood. Acne is characterized by the appearance of several signs, namely blackheads, pustules, papules, cysts and nodes in the neck, face, upper arms, back and chest area. Acne is also a skin disease that affects more than 85\% of adolescents around the world. Although not life-threatening, acne can affect a person's quality of life by giving a psychological effect that is bad for the sufferer in the form of a person's way of judging, responding to and looking at his condition and situation. The purpose of this study was to determine the inhibitory power of citronella extract (Cymbopogon nardus) on the growth of Propionibacterium acnes bacteria. The study was conducted with experimental methods with the posttest design only group design controls conducted at the Microbiology Lab at the Faculty of Medicine, University of Prima Indonesia and the Pharmacy and Toxicology Lab at the Faculty of Pharmacy, University of North Sumatra. The results showed that lemongrass leaf extract had a inhibitory effect on the growth of Propionibacterium acnes bacteria with various concentrations of 20,40,60,80 and 100\%. The higher the concentration of fragrant lemongrass extract, the better the inhibition power.

Key Words: Acne, Propionibacterium acnes, Serai wangi leaf extract

How to Cite: Winato, B.M., Sanjaya, E., Siregar, L., Fau, Solinia, K.Y.M.V., dan Mutia, M.S., (2019). Uji Aktivitas Antibakteri Ekstrak Daun Serai Wangi (Cymbopogon nardus)Terhadap Bakteri Propionibacterium acnes, BioLink : Jurnal Biologi Lingkungan, Industri dan Kesehatan, Vol.6 (1): Hal. 50- 
Winato, B.M., Sanjaya, E., Siregar, L., Fau, Solinia, K.Y.M.V., dan Mutia, M.S., Uji Aktivitas Antibakteri Ekstrak Daun Serai Wangi (Cymbopogon nardus) Terhadap Bakteri Propionibacterium acnes

\section{PENDAHULUAN}

Jerawat adalah penyakit pada kulit yang sering terjadi pada saat usia remaja hingga saat usia dewasa. Jerawat ditandai dengan munculnya beberapa tanda yaitu komedo, pustul, papul, kista dan nodus pada daerah leher, wajah, lengan atas, punggung dan dada (Wahdaningsih, Untari, \& Fauziah, 2017). Jerawat juga merupakan penyakit kulit yang menyerang lebih dari 85\% kalangan usia remaja di seluruh dunia (Radji, 2016). Meskipun tidak mengancam jiwa, jerawat dapat mempengaruhi kualitas hidup seseorang dengan memberikan efek psikologis yang buruk bagi penderita berupa cara seseorang menilai, menanggapi dan memandang kondisi dan situasi dirinya (Abdel-Hafez et al., 2009). Patofisiologi jerawat terjadi karena adanya 4 faktor yang saling berpengaruh yaitu kolonisasi bakteri Propionibacterium acnes, hiperkeratinisasi folikuler, inflamasi, dan peningkatan produksi sebum (Igarashi, Nishino, \& Nayar, 2005).

Bakteri yang umum menginfeksi jerawat adalah Propionibacterium acnes, Staphylococcus aureus, dan Staphylococcus epidermidis. Pengobatan jerawat biasanya menggunakan antibiotik contohnya seperti klindamisin, eritromisin, doksisiklin. Selain itu sering juga menggunakan benzoil peroksidam asam azelat dan retinoid, namun obat-obatan ini mempunyai efek samping pada penggunaannya sebagai anti jerawat yaitu resistensi antibiotik dan iritasi, imunohipersensitivitas dan kerusakan organ (Joshita Djajadisastra, Mun'im, NP, \& Dessy, 2009).

Bakteri dapat menyebabkan penyakit dengan cara menginvasi ke dalam jaringan atau dengan membentuk racun, termasuk bakteri P. acnes. P.acnes merupakan target utama dalam pengobatan antibakteri untuk jerawat. Berdasarkan data, $P$. acnes beraksi dengan menghasilkan beberapa zat penyebab inflamasi (seperti faktor kemotaktik, enzim lipase, dll) yang menginduksi perkembangan pada lesi jerawat (Gollnick \& Krautheim, 2003). P. acnes merupakan bakteri anaerob yang sering ditemukan pada jerawat dan tumbuh dengan lambar serta bersifat Gram-positif (Radji, 2016). P. acnes juga merupakan bakteri penyebab jerawat yang berperan sangat penting dalam menghasilkan inflamasi karena kemampuannya dalam memecah trigliserida menjadi asam lemak bebas (Zaenglein, 2008). P. acnes adalah flora normal pada kulit, rongga mulut, usus besar, konjungtiva, dan saluran telinga luar. Bakteri ini menghasilkan enzim lipase yang berfungsi untuk memecah trigliserida yang dimana merupakan salah satu komponen sebum menjadi asam lemak bebas (free fatty acid). Asam lemak 
bebas ini adalah media yang baik untuk pertumbuhan bakteri $P$. acnes. Selanjutnya bakteri berkembang biak, menimbulkan peradangan, dan membentuk mikro komedo yang merupakan faktor dalam pembentukan jerawat.

Pengobatan jerawat yang disertai peradangan dapat diobati dengan antibiotik yang dapat menghilangkan atau menghambat pertumbuhan bagi bakteri $P$. acnes, antara lain eritromisin dan benzamisin. Beberapa sediaan topikal juga sering digunakan, yaitu salep yang mengandung benzoil peroksida atau tretinoin. Sediaan isotretinoin dapat digunakan untuk jerawat yang semakin parah (Radji, 2016). Penggunaan ekstrak tanaman dalam terapi beberapa penyakit memiliki beberapa keuntungan diantaranya mengenai keefektifannya dan keamanannya (Bota, Martosupono, \& Rondonuwu, 2015). Aiyegoro dan Okoh 2009 (Aiyegoro, Afolayan, \& Okoh, 2009), melaporkan adanya kandungan antimikroba dalam berbagai minyak atsiri atau ekstrak tumbuhan.

Salah satu tanaman obat yang sering diuji dan digunakan adalah serai wangi (Cymbopogon nardus). Serai wangi memiliki senyawa aktif yang dapat digunakan untuk pengobatan seperti antibakteri, antifungi dan antiinflamasi (Maria Yuliyani, Bernardus Boy Rahardjo Sidharta, 2010). Putriningtyas

dalam studinya menyatakan bahwa minyak atsiri daun serai wangi asal Tawangmangu dapat menghasilkan zona hambat terhadap E.coli dan $S$. aureus. Penelitian lain yang dijalani oleh Brugnera et al. (2011), minyak atsiri daun serai wangi asal Brazil memiliki partikel kimia sitronellal sebesar $34,6 \%$, geraniol sebesar $23,17 \%$ dan sitronellol sebesar 12,09\% yang juga dapat menghambat aktivitas pertumbuhan bakteri $S$. aureus juga dapat menghambat aktivitas pertumuhan bakteri Gram negatif yaitu E. coli dan P. aeruginosa. Selain untuk pengobatan, minyak atsiri serai wangi sering diproduksi oleh perusahan atau pabrik untuk memenuhi kebutuhan pasar lokal dan internasional sebagai bahan dasar pembuatan kosmetik (Maria Yuliyani, Bernardus Boy Rahardjo Sidharta, 2010).

Menurut penelitian sebelumnya yang dilakukan oleh Yuliandi,dkk. (2015) mengenai Aktivitas Antibakteri Ekstrak Kloroform Limbah Padat Daun Serai Wangi (Cymbopogon nardus) Terhadap Bakteri Pseudomonas aeruginosa dan Staphylococcus aureus menyatakan bahwa ekstrak daun serai wangi (Cymbopogon nardus) mampu menghambat pertumbuhan bakteri $S$ aureus yang bersifat Gram-positif. Oleh karena itu manfaat ekstrak daun serai wangi dalam menghambat aktivitas bakteri yang 
Winato, B.M., Sanjaya, E., Siregar, L., Fau, Solinia, K.Y.M.V., dan Mutia, M.S., Uji Aktivitas Antibakteri Ekstrak Daun Serai Wangi (Cymbopogon nardus) Terhadap Bakteri Propionibacterium acnes

bersifat Gram-positif lainnya yaitu P. acnes $1,5 \mathrm{~kg} / \mathrm{cm} 2$ pada suhu $121^{\circ} \mathrm{C}$ selama 15 dilakukan.

menit menggunakan autoclave. Alat dan

\section{METODE PENELITIAN}

Jenis dan rancangan penelitian

Penelitian ini merupakan penelitian eksperimental laboratorik yang menggunakan difusi cakram rancangan Posttest Only Control Group Design.

Tempat dan waktu penelitian

Penelitian ini dilaksanakn pada bulan November sampai dengan bulan Desember tahun 2018 di Laboratorium Farmasi dan Toksikologi Fakultas Farmasi Universitas Sumatera Utara dan Lab Mikrobiologi Fakultas Kedokteran Universitas Prima Indonesia.

Sampel penelitian

Daun Serai wangi (Cymbopogon nardus) yang didapatkan di daerah Kampung Lalang Kota Medan serta biakan murni dari bakteri Propionibacterium acnes.

Alat

Sterilisasi alat

Alat dan benda yang akan dipakai harus diatur dengan sedemikian rupa saat hendak dimasukkan ke dalam autoclave sehingga semua bagian alat dapat terkena uap secara merata dan juga menyeluruh dengan tekanan yang digunakan sebesar benda harus dibungkus untuk mencegah terjadinya rekontaminasi setelah keluar dari autoclave.

Persiapan dan pembuatan sampel

Daun Serai wangi (Cymbopogon nardus) didapatkan dari daerah Kota Medan Kelurahan Kampung Lalang. Pembuatan sampel melalui beberapa proses yaitu pencucian, pemotongan, dan pengeringan. Pertama, daun serai wangi (Cymbopogon nardus) sebanyak $5 \mathrm{~kg}$ dicuci dahulu hingga bersih, kemudian dipotong menjadi bagian-bagian yang kecil yang berukuran $2 \mathrm{~cm}$. Kedua, daun serai wangi (Cymbopogon nardus) dimasukkan ke dalam lemari pengering selama 3 hari dengan suhu $40^{\circ} \mathrm{C}$. Ketiga, daun serai wangi (Cymbopogon nardus) digiling menggunakan blender merk miyako dengan kecepatan maksimum dalam waktu 3 menit sampai menjadi bubuk halus. Dalam pembuatan ekstrak daun serai wangi (Cymbopogon nardus), dilakukan menggunakan cara maserasi menggunakan etanol 96\% dengan takaran 10 kali lebih banyak dari berat bubuk halus daun serai, dan dilakukan sebanyak 2 kali penyaringan menggunakan kertas saring. Hasil dari maserasi ini lalu dimasukkan ke dalam rotary evaporator selama kurang lebih 20 jam untuk 
memisahkan etanol dari ekstrak sampai menjadi hampir kental.

Pembuatan konsentrasi

Ekstrak kemudian dicampur dengan alkohol agar diperoleh konsentrasi yang dibutuhkan. Dalam penelitian ini konsentrasi yang digunakan yaitu 20\%, 40\%, 60\%, 80\%, dan 100\%.

Rumus pengenceran

konsentrasi $=\frac{\text { Volume terlarut }}{\text { Volume total }} \times 100 \%$

Sehingga apabila kita ingin mengencerkan ekstrak hingga 20\% maka yang diperlukan adalah 2 gram ekstrak yang dilarutkan dalam $10 \mathrm{ml}$ etanol teknis 96\% yang bertindak sebagai pelarut.

Pembuatan biakan bakteri

Pembuatan biakan bakteri ini bertujuan memperbanyak jumlah bakteri yang akan digunakan. Hal ini dilakukan dengan cara menginokulasikan 1 ose biakan murni bakteri $P$. acnes dari agar ke dalam media nutrient broth yang kemudian diinkubasi $37^{\circ} \mathrm{C}$ selama 24 jam.

Pembuatan media biakan

Media yang digunakan untuk bakteri $P$. acnes ini adalah media cair yaitu Nutrient Agar (NA). Untuk membuat media NA ini, sebanyak 28 gram dalam $1000 \mathrm{ml}$ akuades kemudian medium Nutrien Agar (NA) dimasukkan ke dalam Erlenmayer ukuran $500 \mathrm{ml}$. Media yang telah berisi Nutrient Agar (NA) dipanaskan dengan menggunakan hot plate dan dihomogenkan dengan stirrer hingga larut dengan sempurna. Kemudian Erlenmayer ditutup menggunakan aluminium foil. Kemudian media disterilkan pada suhu $121^{\circ} \mathrm{C}$ selama 15 menit.

Uji Sensitivitas

Uji sensitivitas dilakukan dengan cara : Pertama, usapkan bakteri ke media NA dengan menggunakan cotton swab, diamkan selama 10-15 menit. Lalu letakkan dan rendam blank disk ke dalam masing-masing konsentrasi ekstrak daun serai wangi (Cymbopogon nardus). Kemudian letakkan pada permukaan media agar yang berisi bakteri dengan menggunakan pinset. Setelah itu, inkubasi dalam suhu $37^{\circ} \mathrm{C}$ selama kurang lebih 48 jam. Terakhir, periksa dan ukur zona hambat atau zona bening yang terbentuk menggunakan penggaris

\section{Pengolahan Data}

Data hasil uji aktivitas antibakteri kemudian dianalisis secara statistik menggunakan metode grafik.

\section{HASIL DAN PEMBAHASAN}

Efektivitas antibakteri daun serai wangi (Cymbopogon nardus) terhadap pertumbuhan bakteri P. acnes dengan 
Winato, B.M., Sanjaya, E., Siregar, L., Fau, Solinia, K.Y.M.V., dan Mutia, M.S., Uji Aktivitas Antibakteri Ekstrak Daun Serai Wangi (Cymbopogon nardus) Terhadap Bakteri Propionibacterium acnes

menggunakan difusi cakram yang telah Diameter zona hambat diukur didapatkan zona hambat di sekitar kertas dengan menggunakan jangka sorong. Hasil cakram yang telah di rendam ke dalam uji laboratorium dengan konsentrasi 20, ekstrak daun serai wangi (Cymbopogon 40, 60, 80, dan 100\% didapatkan zona nardus). hambat seperti yang tertera pada gambar dan tabel berikut ini.

Tabel 1. Hasil Diameter Zona Hambat Daun Serai Wangi (Cymbopogon nardus) terhadap Bakteri Propionibacterium acnes

\begin{tabular}{cccccc}
\hline Percobaan & $\mathbf{1 0 0 \%}$ & $\mathbf{8 0 \%}$ & $\mathbf{6 0 \%}$ & $\mathbf{4 0 \%}$ & $\mathbf{2 0 \%}$ \\
\hline I & $19,9 \mathrm{~mm}$ & $17,8 \mathrm{~mm}$ & $16,1 \mathrm{~mm}$ & $15,1 \mathrm{~mm}$ & $13,8 \mathrm{~mm}$ \\
II & $19,2 \mathrm{~mm}$ & $14,9 \mathrm{~mm}$ & $14,1 \mathrm{~mm}$ & $10,1 \mathrm{~mm}$ & $7,2 \mathrm{~mm}$ \\
\hline Rata-Rata Zona Hambat & $19,55 \mathrm{~mm}$ & $16,35 \mathrm{~mm}$ & $15,1 \mathrm{~mm}$ & $12,6 \mathrm{~mm}$ & $10,5 \mathrm{~mm}$ \\
\hline
\end{tabular}
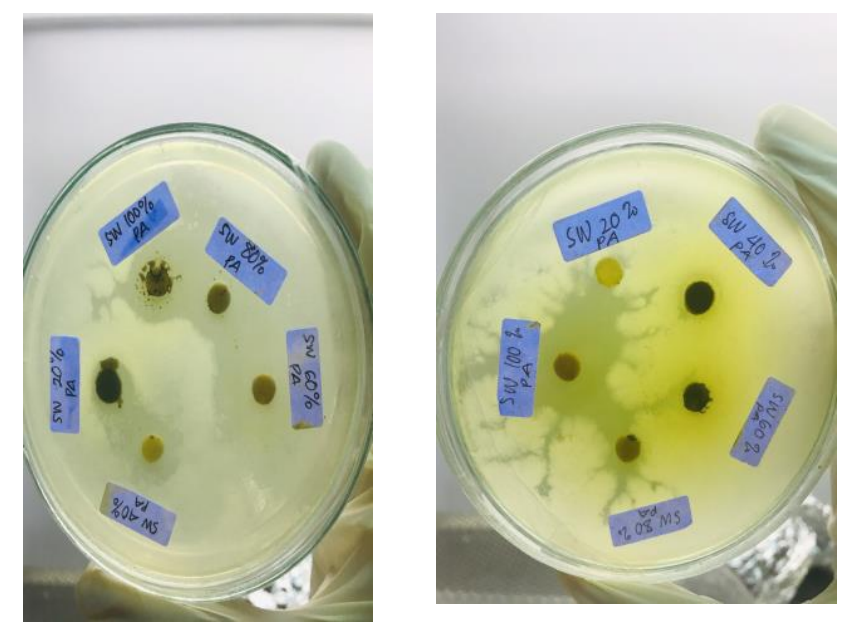

Gambar 1. Zona Hambat Ekstrak Daun Serai Wangi (Cymbopogon nardus) terhadap Bakteri Keterangan : Propionibacterium acnes

$\mathrm{SW} \quad=$ Serai Wangi

PA = Propionibacterium acnes

Berdasarkan gambar 1 dan tabel 1 pada konsentrasi 100\%,80\%,60\%, 40\%, didapatkan hasil zona hambat dari ekstrak dan 20\% dengan rata-rata diameter zona daun serai wangi (Cymbopogon nardus) hambat sebesar 19,55 mm ; 16,35 mm ; terhadap bakteri Propionibacterium acnes $15,1 \mathrm{~mm} ; 12,6 \mathrm{~mm} ; 10,5 \mathrm{~mm}$. 


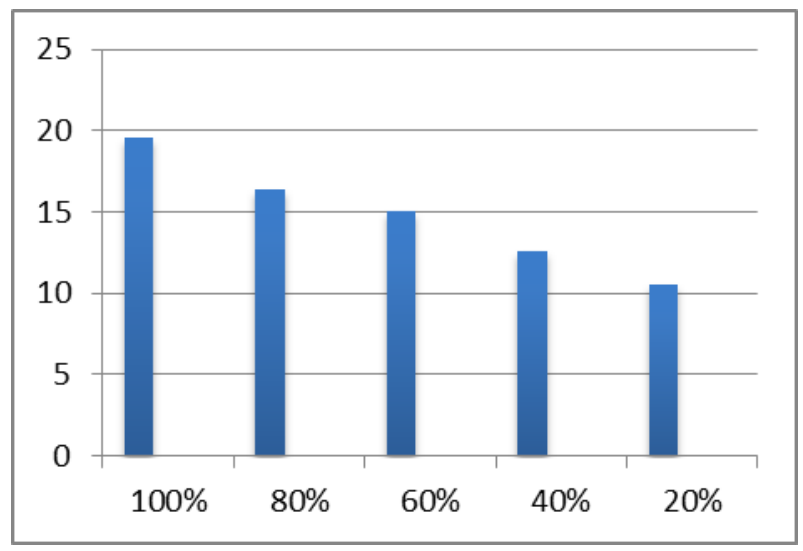

Gambar 2. Diagram Zona Hambat Ekstrak Daun Serai Wangi (Cymbopogon nardus) terhadap Bakteri Propionibacterium acnes

Berdasarkan gambar 2 didapatkan bahwa ekstrak daun serai wangi (Cymbopogon nardus) dengan konsentrasi yang berbeda-beda memiliki rata-rata zona hambat yang berbeda pula terhadap bakteri $P$. acnes. Semakin tinggi konsentrasi ekstrak semakin luas pula diameter zona hambat yang dihasilkan.

Penelitian ini dilakukan dengan menggunakan metode ekstrak yaitu pengambilan zat aktif dari tanaman daun serai wangi dengan menggunakan pelarut etanol teknis 96\% terhadap P. acnes.
Berdasarkan hasil penelitian yang diperoleh bahwa ekstrak daun serai wangi (Cymbopogon nardus) mempunyai daya hambat terhadap bakteri Propionibacterium acnes. Hal ini ditunjukkan dengan adanya zona hambat yang berwarna bening di sekitar kertas cakram yang telah direndam pada ekstrak daun serai wangi (Cymbopogon nardus) dengan konsentrasi 100\%, 80\%, 60\%, $40 \%$ dan $20 \%$ yaitu sebesar 19,55 mm; $16,35 \mathrm{~mm} ; 15,1 \mathrm{~mm} ; 12,6 \mathrm{~mm} ; 10,5 \mathrm{~mm}$.

Tabel 2 Klasifikasi zona hambat menurut Greenwood Sumber : Seila Inayatullah, 2015

\begin{tabular}{cc}
\hline Diameter $(\mathrm{mm})$ & Respon Hambatan Pertumbuhan \\
\hline$<10 \mathrm{~mm}$ & Tidak efektif \\
$10-15 \mathrm{~mm}$ & Efektivitas lemah \\
$16-19 \mathrm{~mm}$ & Efektivitas sedang \\
$>20 \mathrm{~mm}$ & Efektivitas tinggi \\
\hline
\end{tabular}

Berdasarkan tabel 2 ditemui bahwa pertumbuhan bakteri $P$. acnes pada ekstrak daun serai wangi (Cymbopogon konsentrasi : nardus) memiliki respon yang sedang - 100\% dengan rata-rata diameter zona dalam menghambat aktivitas hambat $19,55 \mathrm{~mm}$. 
Winato, B.M., Sanjaya, E., Siregar, L., Fau, Solinia, K.Y.M.V., dan Mutia, M.S., Uji Aktivitas Antibakteri Ekstrak Daun Serai Wangi (Cymbopogon nardus) Terhadap Bakteri Propionibacterium acnes

- $\quad 80 \%$ dengan rata-rata diameter zona hambat $16,35 \mathrm{~mm}$.

Sedangkan respon lemah didapati pada konsentrasi :

- $60 \%$ dengan rata-rata diameter zona hambat $15,1 \mathrm{~mm}$

- $\quad 40 \%$ dengan rata-rata diameter zona hambat $12,6 \mathrm{~mm}$

- $20 \%$ dengan rata-rata diameter zona hambat $10,5 \mathrm{~mm}$.

Hal ini dapat terjadi dikarena kandungan di dalam esktrak daun serai wangi terdapat sitronelal dan geraniol serta fenol yang terdapat di dalam daun serai wangi. Kandungan-kandungan yang terdapat di dalam daun serai wangi mampu menghambat pertumbuhan bakteri $P$. acnes.

\section{SIMPULAN}

Berdasarkan hasil dari penelitian yang dilakukan, maka dapat ditarik simpulan sebagai berikut : Adanya daya hambat yang tergolong sedang dari ekstrak daun serai wangi (Cymbopogon nardus) terhadap pertumbuhan bakteri $P$. acnes pada konsentrasi $100 \%$ dan $80 \%$ sebesar 19,55 mm dan 16,35 mm. Adanya daya hambat yang tergolong lemah dari ekstrak daun serai wangi (Cymbopogon nardus) terhadap pertumbuhan bakteri $P$. acnes pada konsentrasi 60\%, 40\%, dan $20 \%$ yaitu sebesar $15,1 \mathrm{~mm} ; 12,6 \mathrm{~mm}$; $10,5 \mathrm{~mm}$

\section{UCAPAN TERIMAKASIH}

Ucapan terimakasih penulis ucapkan kepada Rektor Universitas Prima Indonesia, Dr. Chrismis Novalinda Ginting, M.Kes, dan Dekan Fakultas Kedokteran dr. Linda Chiuman, M.K.M yang telah memfasilitasi laboratorium di Fakultas Kedokteran Universitas Prima Indonesia sehingga penelitian ini dapat diselesaikan dengan baik. Ucapan terimakasih juga disampaikan kepada Dekan Fakultas Farmasi Universitas Sumatera Utara Prof. Dr. Masfria, M.S., Apt. yang telah memfasilitasi laboratorium di Fakultas Farmasi Universitas Sumatera Utara sehingga penelitian ini dapat diselesaikan dengan baik. Ucapan terimakasih juga disampaikan kepada pembimbing utama dr. Maya Sari Mutia, M.K.M atas ide dan motivasi dalam penelitian ini. Kepada tim analisis Laboratorium Mikrobiologi Fakultas Kedokteran Universitas Prima Indonesia Michael Alfian Grey dan Ditha Paramitha yang turut membantu dalam pelaksnaan penelitian. Ucapan terimakasih juga disampaikan kepada analaisis Laboratorium Farmasi dan Toksikologi Sasniwiati Sari Hasibuan, S.Farm yang turut membantu dalam pelaksanaan penelitian

\section{DAFTAR PUSTAKA}

Abdel-Hafez, K., Mahran, A. M., Hofny, E. R. M., Mohammed, K. A., Darweesh, A. M., \& Aal, A. A. (2009). The impact of acne vulgaris on the quality of life and psychologic status in 
patients from upper Egypt. International Journal of Dermatology. https://doi.org/10.1111/j.13654632.2009.03838.x

Aiyegoro, O. A., Afolayan, A. J., \& Okoh, A. I. (2009). In vitro antibacterial activities of crude extracts of the leaves of Helichrysum longifolium in combination with selected antibiotics. African Journal of Pharmacy and Pharmacology.

Bota, W., Martosupono, M., \& Rondonuwu, F. (2015). Potensi senyawa minyak sereh wangi (Citronella oil) dari tumbuhan Cymbopogon nardus L. sebagai agen anti bakteri. Seminar Nasional Sains Dan Teknologi 2015, Inovasi Humaniora, (November), 1-8.

Gollnick, H. P. M., \& Krautheim, A. (2003). Topical treatment in acne: Current status and future aspects. In Dermatology. https://doi.org/10.1159/oooo67820

Igarashi, T., Nishino, K., \& Nayar, S. K. (2005). The appearance of human skin. Skin Care Research Laboratory. https://doi.org/10.1561/o6oooooo13

Joshita Djajadisastra, Mun'im, NP, A., \& Dessy. (2009). Fornulasi Gel Topikal Dari Ekstrak
Nerii Folium Dalam Sediaan Anti Jerawat. Jurnal Farmasi Indonesia.

Maria Yuliyani, Bernardus Boy Rahardjo Sidharta, F. S. P. (2010). Aktivitas Antibakteri Ekstrak Kloroform Limbah Padat Daun Serai Wangi (Cymbopogon nardus) Terhadap Bakteri Pseudomonas aeruginosa dan Staphylococcus aureus. Jurnal Fakultas Teknobiologi Universitas Atma Jaya Yogyakarta, 1-15.

Radji, D. . D. M. (2016). Buku Ajar Mikrobiologi : Panduan Mahasiswa Farmasi dan Kedokteran. In Buku Ajar Mikrobiologi: Panduan Mahasiswa Farmasi dan Kedokteran. https://doi.org/10.1063/1.1619138

Wahdaningsih, S., Untari, E. K., \& Fauziah, Y. (2017). Antibakteri Fraksi n-Heksana Kulit Hylocereus polyrhizus Terhadap Staphylococcus epidermidis dan Propionibacterium acnes. Pharmaceutical Sciences and Research, 1(3), 180-193. https://doi.org/10.7454/psr.vii3.3490

Zaenglein, A. L. (2008). Topical Retinoids in the Treatment of Acne Vulgaris. Seminars in Cutaneous Medicine and Surgery. https://doi.org/10.1016/j.sder.2008.06.001 